\title{
Light and heavy element detection in thin sections of soils with the ion microprobe mass analyzer (IMMA)
}

E. B. A. Bisdom', S. Henstra², A. Jongerius', J. D. Brown', A. P. von Rosenstiel ${ }^{4}$ and D. J. Gras'

1 Soil Survey Institute, Wageningen, Netherlands

2 Technical and Physical Engineering Research Service, Wageningen, Netherlands

- The University of Western Ontario, London, Canada (on sabbatical leave at the Metal Research Institute TNO)

- Metal Research Institute TNO, Apeldoorn, Netherlands

Accepted: 30 December 1976

Key words: Ion Microprobe Mass Analyzer (IMMA), submicroscopic technique, thin sections of soil, clayified root

\section{Summary}

Previous research with the scanning electron microscope (SEM)-energy dispersive $X$-ray analyzer (EDXRA) and the electron microprobe analyzer (EMA), showed that the detection of light elements in thin sections of soils was problematic or even impossible. Consequently initial experiments were performed with the ion microprobe mass analyzer (IMMA). These preliminary investigations were carried out on a piece of root material in soil (containing both light and heavy elements) which has a 'clayey' appearance and is known as a clayified root (Parfenova et al., 1964).

The presence of heavier elements in this sample was investigated by SEMEDXRA prior to IMMA analysis.

The results with the ion microprobe mass analyzer showed that all chemical elements could be analyzed in the plant fragment. Also much higher elemental detection sensitivities were found with IMMA as compared to SEM-EDXRA and EMA. This even allowed ion imaging of trace elements. High-quality ion images of both light and heavy elements could be obtained in much shorter exposure times than with SEM-EDXRA and EMA techniques. Furthermore by analysis of fragmentation ('fingerprint') spectra additional information was obtained with respect to the chemical binding of the analyzed elements. Due to these preliminary results IMMA offers full possibilities for microchemical analysis in situ of all important elements in soil specimens. This technique considerably increases possibilities in soil micromorphology. 


\section{Introduction}

The experiments carried out with the ion microprobe mass analyzer (IMMA) form part of our investigations for finding a combination of research techniques enabling an in situ microanalysis of all chemical elements in thin sections of soils. The use of these advanced techniques is only possible after light microscopic investigations of these thin sections. This branch of soil science is called 'soil micromorphology'. The thin sections are prepared according to a method developed by Jongerius \& Heintzberger $(1963,1975)$. Investigation of these thin sections allows a comparison with observations made in the field and gives more detailed information concerning, for instance, the genesis of soils. By light microscopical investigation certain soil components such as amorphous mineral material, organic matter, weathered minerals and sub-microscopical particles are impossible to analyze or in some cases only with great difficulty. Consequently other techniques should be applied for microanalysis of these soil components in situ.

First results achieved by SEM-EDXRA, a combination of scanning electron microscopy and energy dispersive X-ray analysis, in soil micromorphology were presented at the 'First EDAX European Users Meeting' at Liège, Belgium (Henstra et al., 1973), while a complete description of the analytical method was given in a later publication (Bisdom et al. 1975). SEM-EDXRA can detect all chemical elements above atomic number 11 (sodium). This means that lighter elements, often very important for the identification of organic matter in thin sections, cannot be determined. Consequently, additional measurements were performed with the electron microprobe analyzer (EMA) capable of analyzing all elements above boron $(\mathrm{Z}=5)$.

These analyses were carried out on organic and mineral material in order to evaluate the light element capability of EMA. $\mathrm{N}$ was not detectable however, whereas $O$ and $C$ could not be specifically attributed to the organic parts of the sample (Bisdom et al. 1976). Therefore IMMA was chosen for this purpose.

\section{Ion probe microanalysis}

The ion microprobe mass analyzer (Fig. 1A) accomplishes the analysis of a microvolume of a solid sample (in this case a thin section of a soil) by bombarding the surface with a high energy beam of ions which causes the atoms at the surface of the samples to be sputtered away. A fraction of the sputtered particles is electrostatically charged, and these sputtered ions (secondary ions) are collected and analyzed according to their mass to charge ratio in a mass spectrometer. This general idea was introduced by Castaing \& Slodzian (1962), resulting in the development of a direct imaging secondary ion microscope with a non-focussed stationary ion beam as described by Rouberol et al. (1968) and Socha (1971).

The present investigations were performed with an ion microprobe mass analyzer basically designed by Liebl (1967) and Robinson et al. (1968). This instrument is analogous in design to the electron microprobe X-ray analyzer in that a (scanning) primary ion beam has been substituted for the electron beam and a mass spectro- 

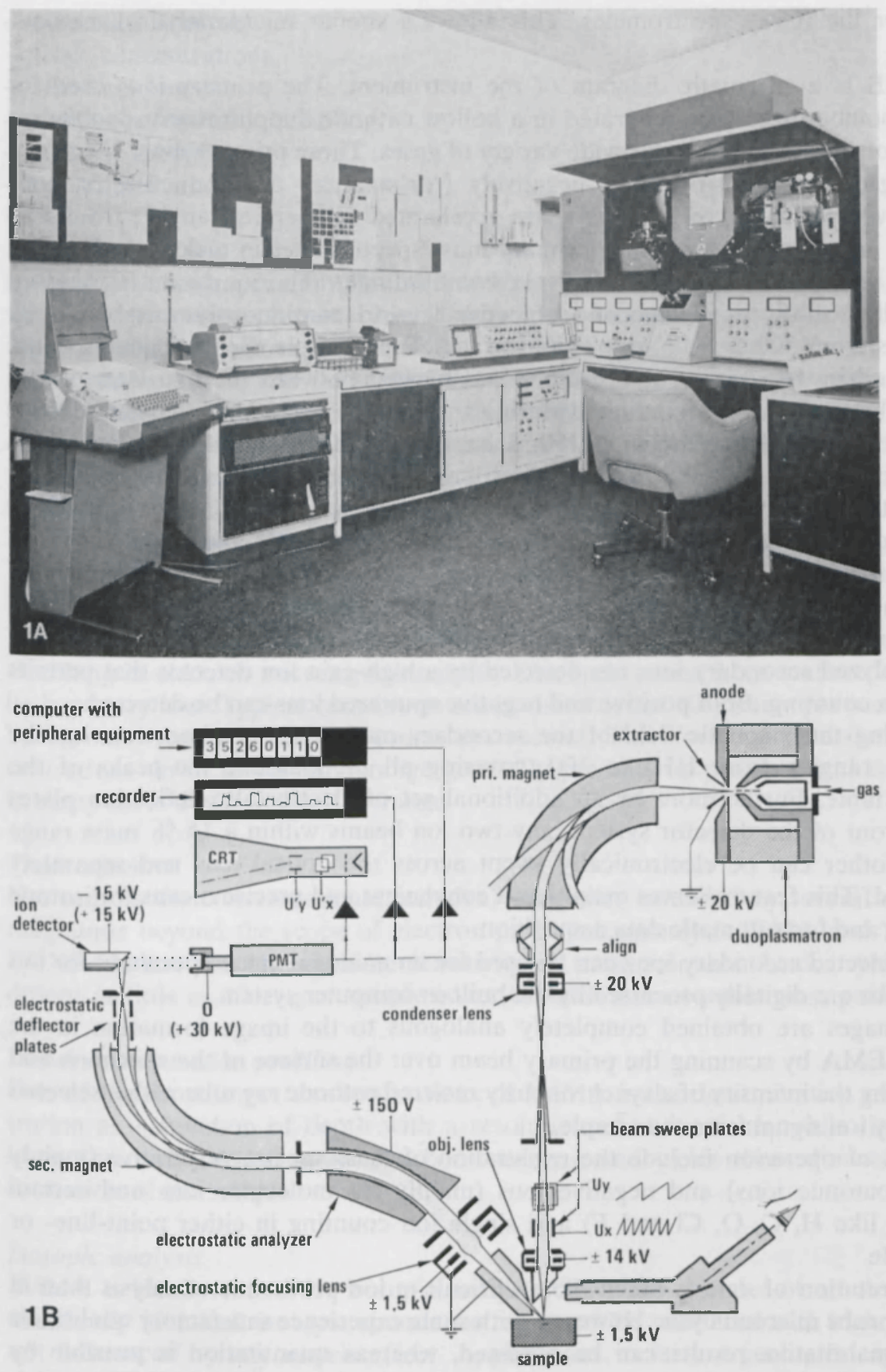

Fig. 1. The Applied Research Laboratories ion microprobe mass analyzer of the Metal Research Institute TNO, Netherlands (Fig. 1A) and schematic diagram (Fig. 1B). Compare text. (Courtesy of Applied Research Laboratories.) 
meter for the X-ray spectrometer. This allows a similar microanalytical methodology.

Fig. 1B is a schematic diagram of the instrument. The primary ions used for sample bombardment are generated in a hollow cathode duoplasmatron ion source capable of producing ions of a wide variety of gases. These primary ions, which can be charged either positively or negatively (for analysis of conductive or nonconductive specimens, respectively), are accelerated to energies ranging from 5 to $22.5 \mathrm{kV}$ and mass analyzed in a primary mass spectrometer in order to select and purify a specific ion species for sample bombardment. The ion beam is focussed by an electrostatic condenser and objective lens to continuously variable probe diameters from 500 to $1-2 \mu \mathrm{m}$ on the surface of the sample. Beam scanning is accomplished by two sets of deflection plates located between the two electrostatic lenses. The sample is viewed directly during analysis through a binocular microscope normally at magnifications of $\times 250$. Selection of specific areas on the sample is accomplished by a digitally controlled high precision sample stage in $x-y-z$ direction and rotation.

The sputtered secondary ions are extracted at a take-off angle of $45^{\circ}$ by an electrostatic focussing extraction lens and mass analyzed in a double focussing mass spectrometer. No entrance slit is used and the bombarded area is stigmatically focussed directly onto the resolving slit in order to increase ion transmission. The mass analyzed secondary ions are detected by a high-gain ion detector that permits single ion counting. Both positive and negative sputtered ions can be detected.

Scanning the magnetic field of the secondary magnet a mass spectrum can be recorded ranging from $1(\mathrm{H})$ to 300 , covering all monoatomic ion-peaks of the periodic table. Furthermore by an additional set of electrostatic deflection plates just in front of the detector system, any two ion beams within a $15 \%$ mass range of each other can be electronically swept across the optical axis and separately integrated. This feature serves mainly as a convenient and precise means for isotope rationing and for automatic data acquisition.

The detected secondary ions can be used for an analogue mass-spectrum, for ion imaging, or are digitally processed by the built-in computer system.

Ion images are obtained completely analogous to the image formation in the SEM or EMA by scanning the primary beam over the surface of the specimen and modulating the intensity of a synchronously rastered cathode ray tube with a selected secondary ion signal from the sample.

Modes of operation include the registration of mass spectra of positive (mainly for monoatomic ions) and negative ions (mainly for molecular ions and certain elements like $\mathrm{H}, \mathrm{C}, \mathrm{O}, \mathrm{Cl}$ and $\mathrm{F}$ ) and single ion counting in either point-line- or area mode.

Interpretation of data is much more difficult in ion probe microanalysis than in electron probe microanalysis. However, with some experience satisfactory qualitative or semiquantitative results can be obtained, whereas quantitation is possible by suitable internal or external standards and a theoretical approach (LTE model; Anderson \& Hinthorne, 1973).

Ion microprobe analysis is offering the following features (Liebl, 1975): 
- elemental analysis

- trace concentrations

- trace amounts

- depth concentration profiling

- isotopic analysis

- compound analysis.

\section{Elemental analysis}

IMMA does not impose any limitation with respect to atomic number as is the case with electron probe microanalysis. However, the secondary ion yield, and thus the limit of detection, can vary over several orders of magnitude for different elements in one matrix and also for the same element in different matrices - further influenced by the chemical state of the elements, the crystal orientation and effects of surface contamination. Generally the secondary ion yield of an element is much higher when it is sputtered from a bound state than from a metallic state. Thus the presence of a reactive species in the sample or bombarding with a reactive species - such as oxygen or nitrogen - strongly enhances the secondary ion yield.

\section{Trace concentrations}

In ion probe microanalysis there is no inherent background such as the Bremsstrahlung in electron microprobe analysis. The background from scattered ions can be kept very low. Typical count rates are in the order of $10^{8}$ counts per second with background readings below 5 counts per second. Therefore, the detection of concentrations down to the $10^{-6}$ range generally presents no problem and is possible in many cases down to the $10^{-9}$ range.

\section{Trace amounts}

Not only is the concentrational (relative) sensitivity extended by several orders of magnitude beyond the scope of electron probe microanalysis (EMA and/or SEMEDXRA), but also the absolute sensitivity to trace amounts. Under typical conditions as little as $10^{-18} \mathrm{~g}$ of sample material yields a measurable mass peak.

\section{Depth concentration profiling}

One of the most important applications of IMMA is the determination of concentration as a function of depth with a resolution of about $5 \mathrm{~nm}$ while the sample is continuously eroded under ion bombardment and yields three dimensional information of the sample.

\section{Isotopic analysis}

IMMA is ideally suited for isotopic analysis. Since the isotopes of an element are chemically identical, isotopic abundance ratios can be measured with high accuracy not influenced by any matrix effect. Applications so far are geological age dating and transport phenomena of elements labelled with stable isotopes in micron-sized areas. 


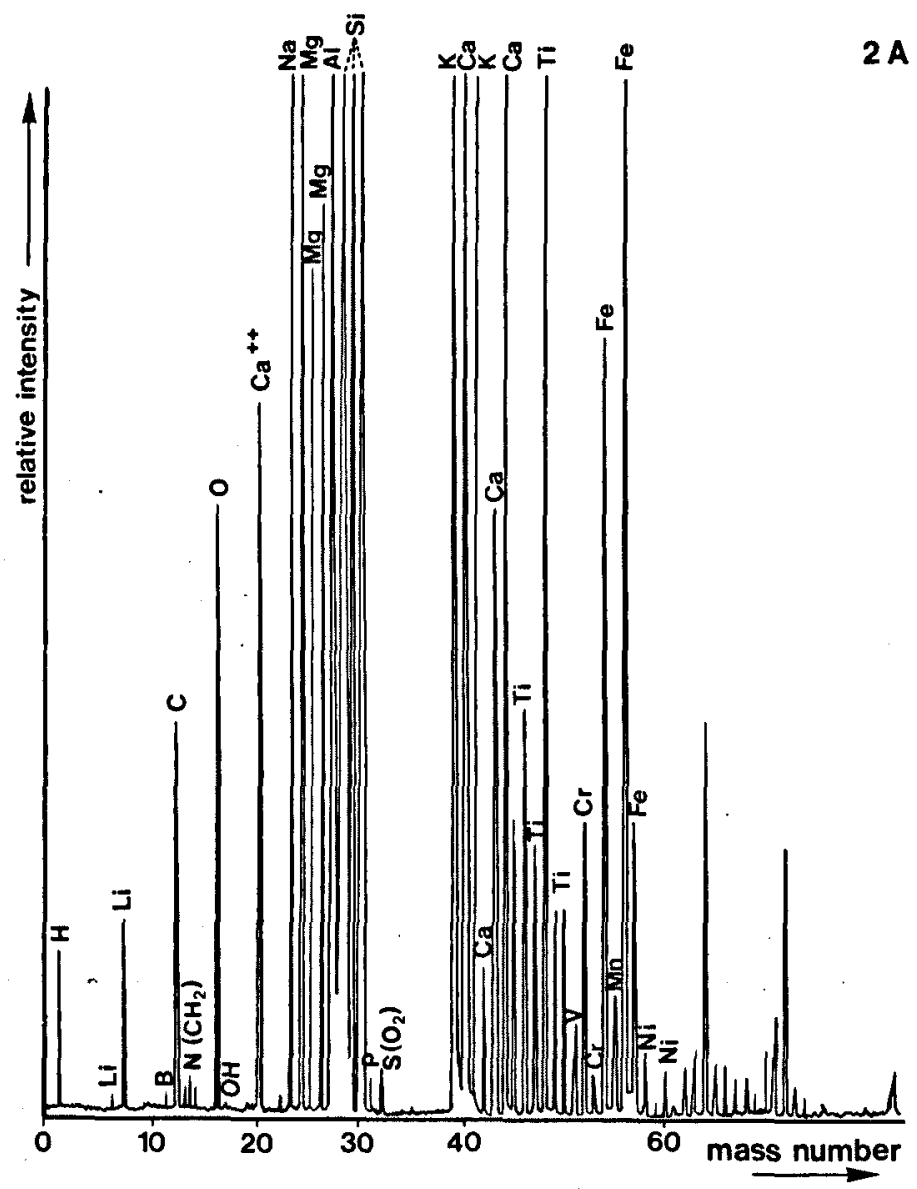

Fig. 2. Positive (Fig. 2A) and negative (Fig. 2B) ion spectra of material in a clayified alder root fragment.

\section{Compound analysis}

In sputtering a solid, not only do single atoms leave the surface but also compound and cluster particles. Analysis of these fragmentation ('fingerprint') spectra yield information about the chemical binding of the analyzed elements, viz. the identification of compounds.

\section{Example of this method}

An alder root fragment from a Gley Soil or Humaquept (Anon., 1975), near Bathmen, Netherlands, has been examined with the ion microprobe mass analyzer (IMMA). Humified remnants of the original root tissue can be found besides brownish coloured rather homogeneous fine material. These remnants are morphologically identical with the clayified root of Parfenova et al. (1964). For practical 


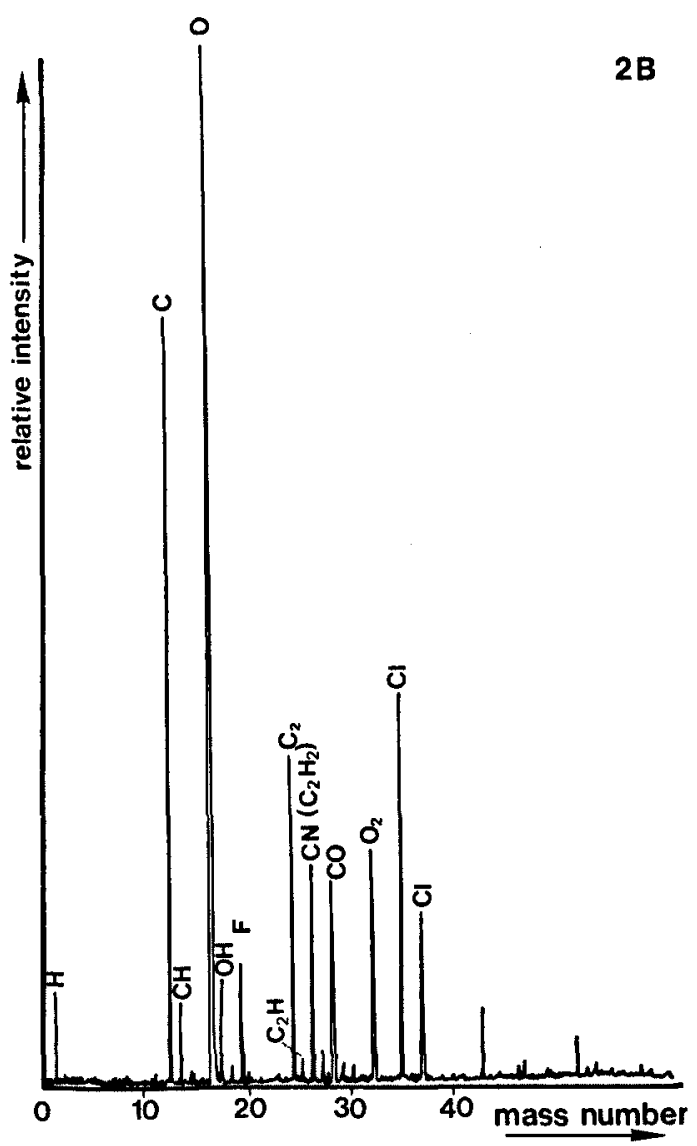

reasons, only one example of a point analysis with positive and negative secondary ion spectra and accompanying ion images can be given here. A discussion of the results of experiments is given below.

A piece of soil material was transferred from the object glass of the thin section to a high purity aluminium substrate, and cemented with silver paint. This served to stretch the thin section and to maintain a flat smooth surface after drying. Using negative primary ions of ${ }^{16} \mathrm{O}$ charging was almost eliminated whereas the sample voltage was properly adjusted for each analyzed area. This method of sample handling permitted a successful ion microprobe analysis of thin sections of plastic impregnated soil specimens.

\section{Analogue ion spectra}

Positive and negative ion spectra were taken from a point in the root fragment. The positive secondary ion spectrum shows a large number of elements as well as excellent peak to background ratios (Fig. 2A). The measured positive ions are $\mathrm{H}, \mathrm{Li}$, $\mathrm{B}, \mathrm{C}, \mathrm{N}$ (with some $\mathrm{CH}_{2}$ ), O, $\mathrm{Na}, \mathrm{Mg}, \mathrm{Al}, \mathrm{Si}, \mathrm{P}, \mathrm{S}$ (with some $\mathrm{O}_{2}$ ), $\mathrm{K}, \mathrm{Ca}, \mathrm{Ti}, \mathrm{V}, \mathrm{Cr}$, 
$\mathrm{Fe}, \mathrm{Mn}$ and $\mathrm{Ni}$. The negative secondary ion spectrum on the other hand, exhibits $\mathrm{H}, \mathrm{C}, \mathrm{O}, \mathrm{F}, \mathrm{Cl}$ as well as molecular ions of $\mathrm{OH}, \mathrm{CH}, \mathrm{C}_{2} \mathrm{H}, \mathrm{CN}$ (with some $\mathrm{C}_{2} \mathrm{H}_{2}$ ) and $\mathrm{CO}$ (Fig, 2B). The latter spectrum shows clearly that light elements such as $\mathrm{H}$, $\mathrm{Li}, \mathrm{B}, \mathrm{C}, \mathrm{O}, \mathrm{F}, \mathrm{N}$ and $\mathrm{Na}$ can be detected easily even at very low concentrations. EMA and SEM-EDXRA X-ray techniques cannot detect $\mathrm{H}$ and $\mathrm{Li}$, while others such as B, C, F and N may give problems (Bisdom et al., 1975, 1976).

The peaks representing molecular ions in the negative secondary ion spectrum demonstrate that information can be gained concerning chemical compounds in the analyzed root. This can be an important point of IMMA analysis, which is likely to be used for the investigation of relatively simple oxides on the thin section.

Semiquantitative information can be drawn from this spectrum in comparison with suitable internal or external standards by means of electronic data reduction. The development of this aspect of IMMA measurements will require a number of additional experiments.

The spectra are very sensitive with regard to local compositional differences, expressed not only in the peak heights, but also by intensity ratios of the individual lines. The ability of IMMA to detect trace elements, which is not possible with EMA and SEM-EDXRA, explains the higher range of detectable elements with this apparatus. The extremely high sensitivity of the instrument allows in situ studies on thin sections of virtually all products which precipitate or accumulate in the soil or deeper horizons as a result of natural or human induced processes. IMMA can therefore, in our opinion, play a major role in environmental studies.

\section{Ion images}

Due to high count rates and good peak/background ratios, ion images can be made even from trace elements. The exposure time is normally less than one minute, which is much faster than $\mathrm{X}$-ray images made with EMA and SEM-EDXRA. $A$ very thin layer in the order of a few nanometers of the analyzed specimen is removed during sputtering. Virtually no morphological changes were observable with the light microscope, however, after completion of the experiment.

Positive ion images of ${ }^{1} \mathrm{H},{ }^{12} \mathrm{C},{ }^{14} \mathrm{~N},{ }^{16} \mathrm{O},{ }^{23} \mathrm{Na},{ }^{24} \mathrm{Mg},{ }^{27} \mathrm{Al},{ }^{28} \mathrm{Si},{ }^{91} \mathrm{P},{ }^{30} \mathrm{~K},{ }^{40} \mathrm{Ca},{ }^{48} \mathrm{Ti}$, ${ }^{52} \mathrm{Cr},{ }^{55} \mathrm{Mn}$ and ${ }^{58} \mathrm{Fe}$, and negative ion images of ${ }^{1} \mathrm{H},{ }^{12} \mathrm{C},{ }^{24} \mathrm{C},{ }^{18} \mathrm{CH},{ }^{16} \mathrm{O},{ }^{19} \mathrm{~F}$ and ${ }^{35} \mathrm{Cl}$ are given in Fig. 3. The digits refer to mass numbers. It should be noted that some metal ions - in particular $\mathrm{Na}, \mathrm{K}, \mathrm{Ca}, \mathrm{Cr}$ and $\mathrm{Fe}$ - are also present in the plastic.

The presence and distribution of heavier elements from the alder root fragment was investigated prior to IMMA analysis by SEM-EDXRA. This analysis showed $\mathrm{Al}$ and $\mathrm{Si}$ as the main components of the root, whereas $\mathrm{Fe}$ was present in small or intermediate quantities and $\mathrm{S}, \mathrm{Cl}, \mathrm{K}, \mathrm{Ca}$ and $\mathrm{Ti}$ in very small amounts.

The overall distribution of elements in the ion images of the decaying alder root is rather homogeneous. This is partly due to the large sensitivity of IMMA, which depicts ion images from trace elements virtually identical to images from elements represented in larger quantities. It also shows, however, that similar elements are present in areas with brownish coloured rather homogeneous fine grained material and humified root tissue, an important fact for the explanation of certain micromorphological phenomena. 

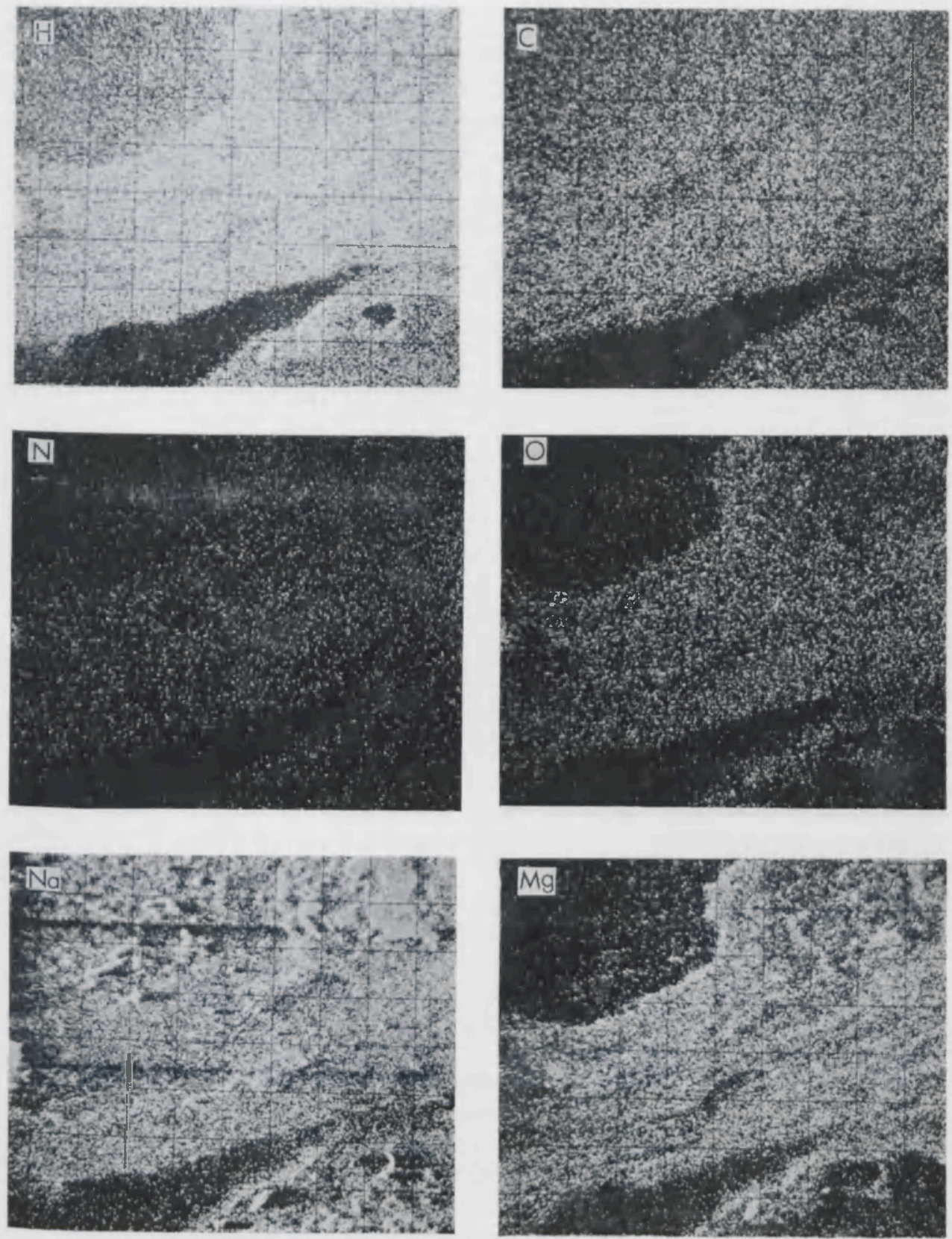

Fig. 3. Ion images of elements present in clayified alder root. Magnification $\times 215$. 
E. B. A. BISDOM ET AL.
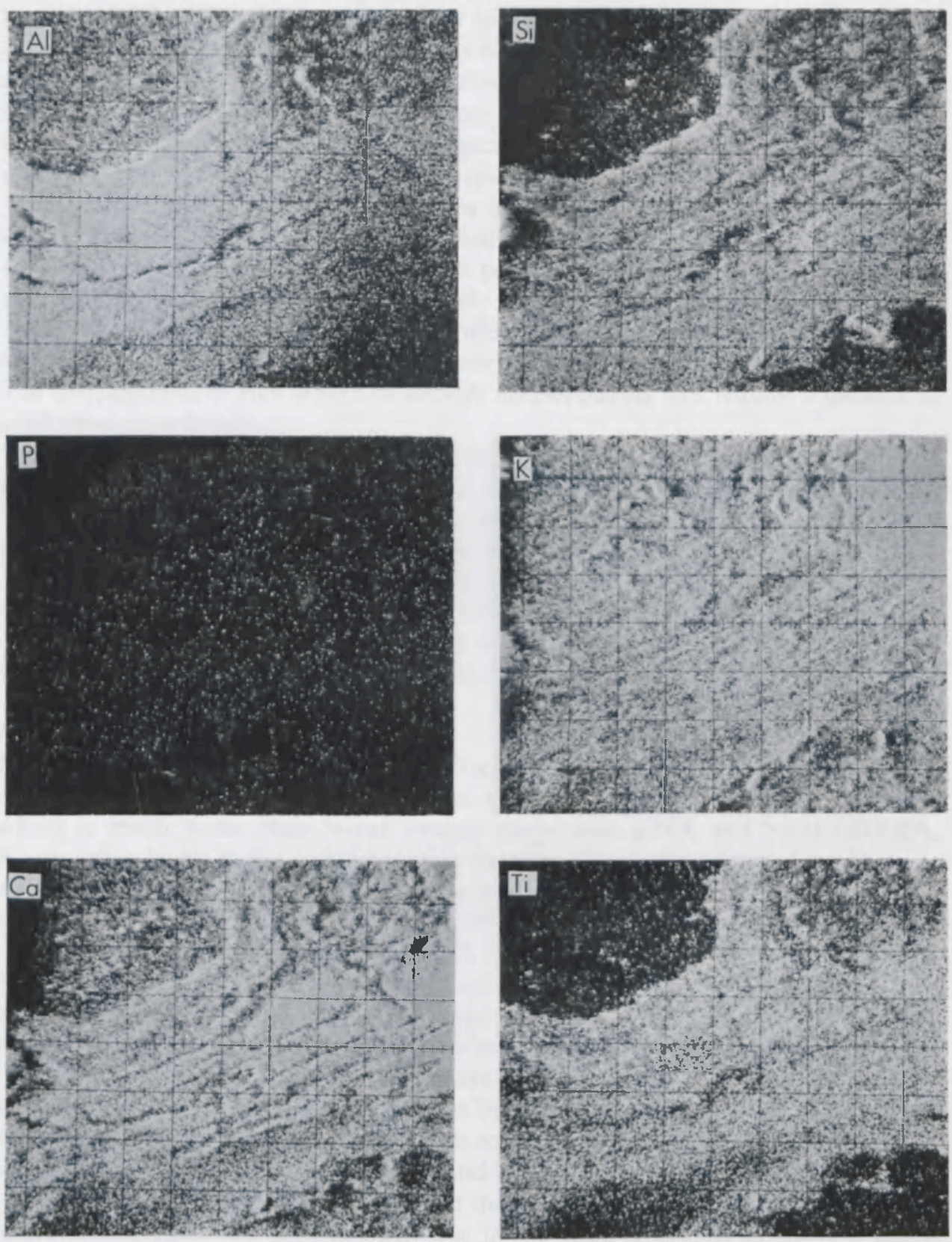

Fig. 3 (continued). 

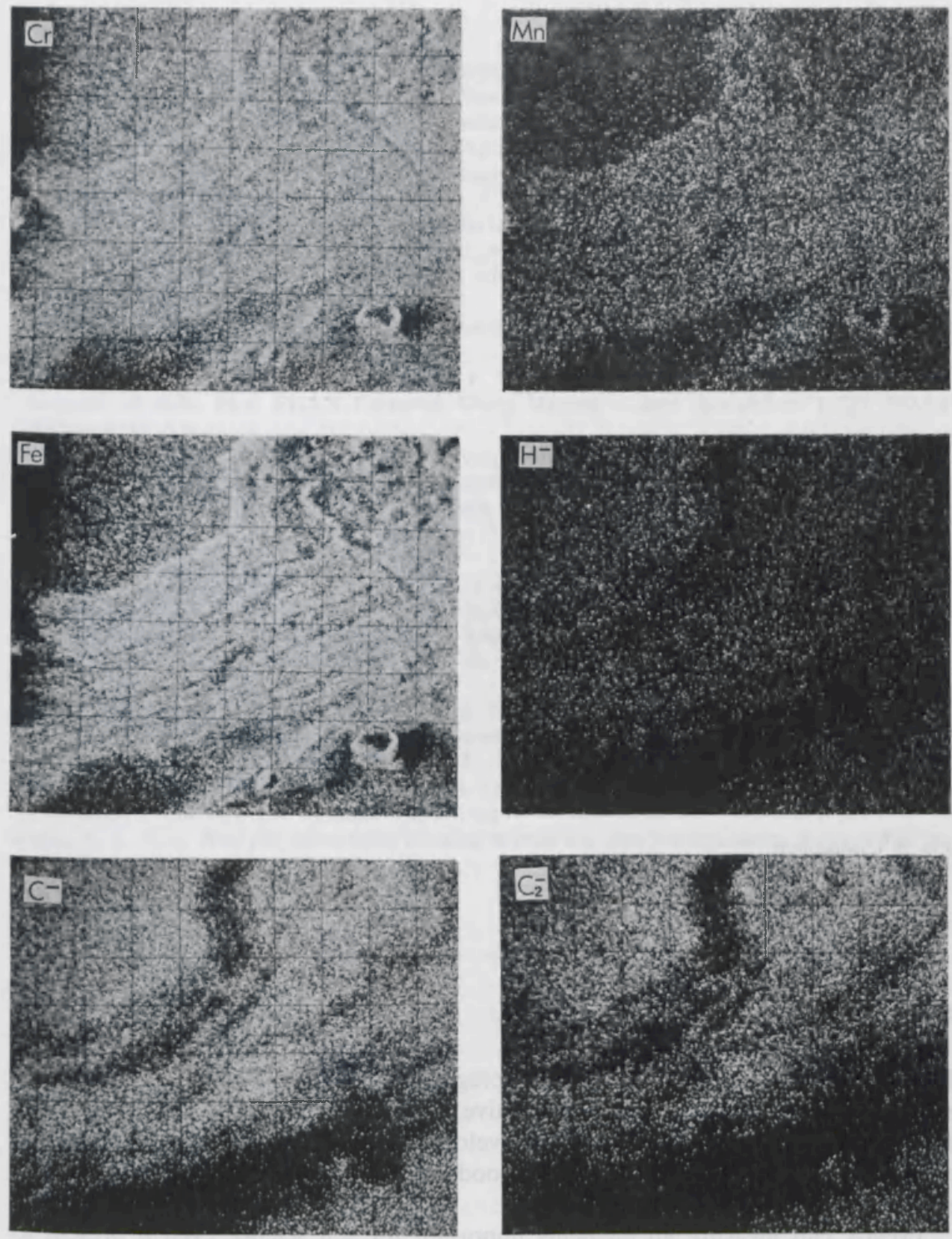

Fig. 3 (continued). 

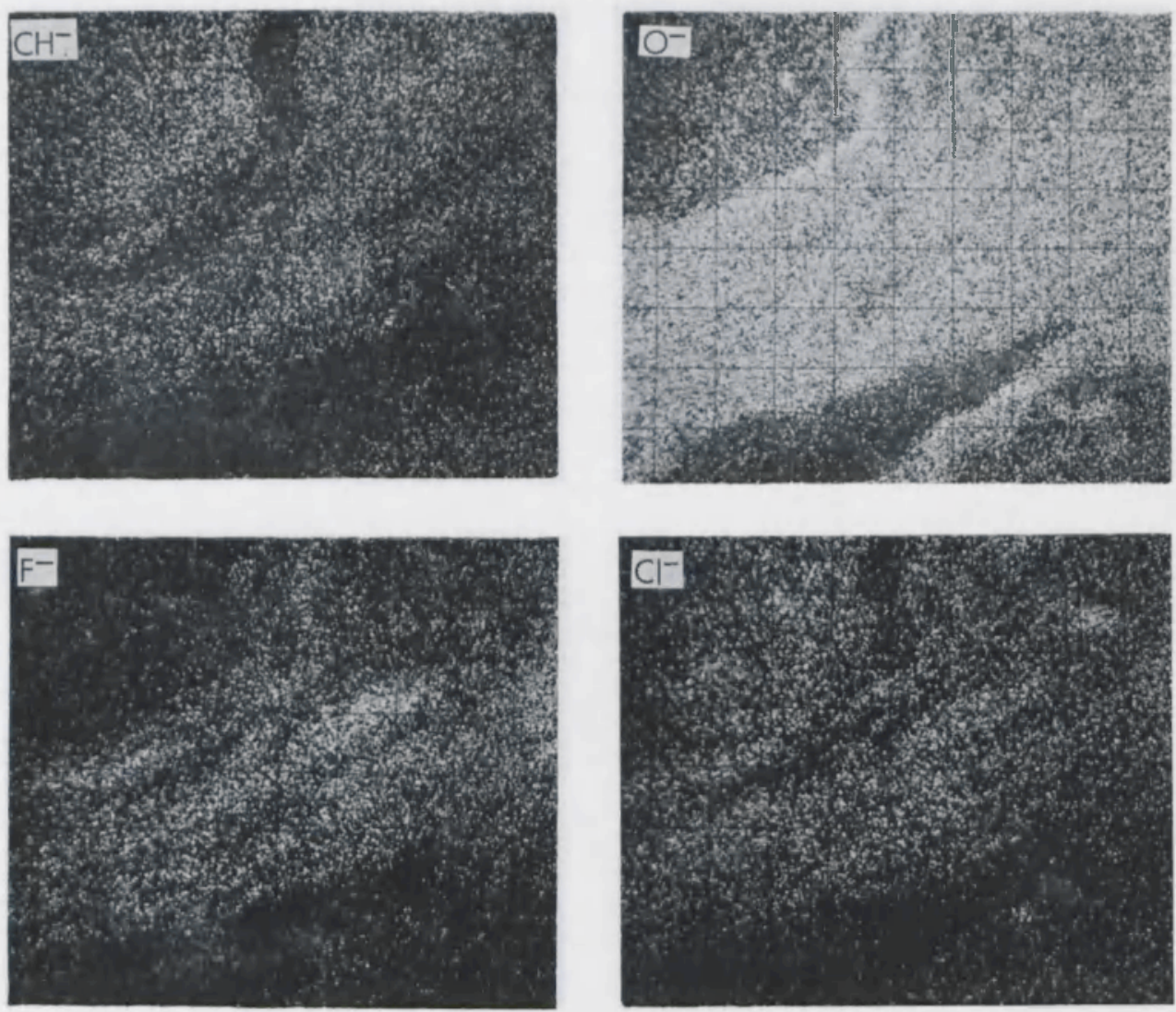

Fig. 3 (continued).

\section{Conclusions}

Preliminary experiments on plastic-impregnated soil material with IMMA have shown that IMMA is a far more sensitive instrument than either EMA or SEMEDXRA. Standards will have to be developed for the analysis of soil material in the near future in order to achieve good semiquantitative or even quantitative results.

IMMA can measure all elements important for soil science even if present as trace elements or in the form of isotopes. It is important that besides atomic ions, molecular ions can also be measured. This allows the study of not only elements but also of compounds in soil material. IMMA, although at present still in an early stage of development, is one of the most promising instruments available for soil and environmental research. 


\section{ELEMENT DETECTION IN THIN SOIL SECTIONS WITH IMMA}

\section{References}

Anderson, C. A. \& J. Hinthorne, 1973. Thermodynamic approach to the quantitative interpretation of sputtered ion spectra. Analyt. Chem. 45: 1421-1438.

Anonymous, 1975. Soil taxonomy: a basic system of soil classification for making and interpreting soil surveys. U.S. Soil Survey Staff, Agricultural handbook, No 436. Soil Conservation Service, U.S. Department of Agriculture, Washington D.C., 754 pp.

Bisdom, E. B. A., S. Henstra, A. Jongerius \& F. Thiel, 1975. Energy-dispersive X-ray analysis on thin sections and unimpregnated soil material. Neth. J. agric. Sci. 23 (2): 113-125.

Bisdom, E. B. A., S. Henstra, E. M. Hornsveld, A. Jongerius \& A. C. Letsch, 1976. Wavelength and energy dispersive X-ray microanalysis with EMA and SEM-EDXRA on thin sections of soils. Neth. J. agric. Sci. 24 (4): 209-222.

Castaing, R. \& G. Slodzian, 1962. Microanalyse par émission ionique secondaire. J. Microsc. 1: 395-410.

Henstra, S., E. B. A. Bisdom, A. Jongerius \& F. Thiel, 1973. Energy dispersive analysis on thin sections of soils. First EDAX European Users Meeting (Liège, September, 1973). EDAX Editor 3 (1): 5-6.

Jongerius, A. \& G. Heintzberger, 1963. The preparation of mammoth-sized thin sections. Soil Survey Pap. 1 (Netherlands Soil Survey Institute); 37 pp.

Jongerius, A. \& G. Heintzberger, 1975. Methods in soil micromorphology. A technique for the preparation of large thin sections. Soil Survey Pap. 10 (Netherlands Soil Survey Institute); $48 \mathrm{pp}$.

Liebl, H., 1967. Ion microprobe mass analyzer. J. appl. Phys. 38: 5277-5283.

Liebl, H., 1975. Ion probe microanalysis. J. Phys. 8: 797-808.

Parfenova, E. I., E. F. Mochalova \& N. A. Titova, 1964. Micromorphology and chemism of humus-clay new-formations in grey forest soils. In: A. Jongerius (Ed.), Soil micromorphology. Elsevier, p. 201-212.

Robinson, C. F., H. J. Liebl \& C. A. Anderson, 1968. New developments in the ion microprobe mass analyzer. Proc. 3rd natn. Conf. Electron Microprobe Anal. (Chicago), Paper nr. 26.

Rouberol, J. M., J. Guerne, P. Deschamps, J. P. Dagnot \& J. M. Guyon de la Berge, 1968. Microanalyseur par émission ionique secondaire. Proc. 5th int. Conf. X-ray Optics Microanal. (Tübingen, 1968): 311-318. Springer, Heidelberg.

Socha, A. J., 1971. Analysis of surfaces utilising sputter ion source instruments. Surface Sci. 25: $147-170$. 